\title{
INFLUÊNCIA DOS CUSTOS DE IMPORTAÇÃO NO RESULTADO DE UMA EMPRESA DA ZONA FRANCA DE MANAUS: ESTUDO DE CASO NA EMPRESA X
}

\section{ARTIGO ORIGINAL}

HAYASHI, Ronney Luiz ${ }^{1}$, SILVA, Lanessa Luzia do Carmo da², ROBERTO, José Carlos Alves ${ }^{3}$, SERRA, Meg Rocha da Cunha ${ }^{4}$, LOPES, Nelânia Ferreira ${ }^{5}$

HAYASHI, Ronney Luiz. Et al. Influência dos custos de importação no resultado de uma empresa da zona franca de Manaus: estudo de caso na empresa $x$. Revista Científica Multidisciplinar Núcleo do Conhecimento. Ano. 06, Ed. 10, Vol. 04, pp. 70-99. Outubro 2021. ISSN: 2448-0959, Link de acesso: https://www.nucleodoconhecimento.com.br/contabilidade/custos-de-importacao, DOI: 10.32749/nucleodoconhecimento.com.br/contabilidade/custos-de-importacao

\section{RESUMO}

A localização geográfica aliada aos incentivos e a necessidade de apresentar um diferencial nos produtos, seja ele preço ou qualidade, fizeram do processo de importação uma variante constante para as indústrias situadas no estado do Amazonas. O mesmo ocorre com a empresa $X$, localizada na cidade de Manaus, onde realizou-se diagnóstico organizacional e aplicação do referido estudo de caso. O presente artigo tem como objetivo a demonstração da influência dos custos de importação no resultado da empresa e tem como questão norteadora: Qual a influência dos custos de importação no resultado do exercício? A metodologia

\footnotetext{
${ }^{1}$ Graduando do curso de Ciências Contábeis.

${ }^{2}$ Graduanda do curso de Ciências Contábeis.

${ }^{3}$ Orientador. Mestre em Engenharia de produção. Especialista Logística empresarial. Graduado em Administração com Ênfase em Marketing.

${ }^{4}$ Orientadora. Mestra em Engenharia de Processos Industriais pela UFPA, especialista em Controladoria e Auditoria Contábil pelo Ciesa, Graduada em Ciências Contábeis pelo Centro Universitário do Norte. Graduada em Ciências Econômicas pelo Centro Universitário do Norte.

${ }^{5}$ Orientadora. Especialista em Auditoria Contábil, Financeira e Tributaria e Graduada em Ciências Contábeis.
}

RC: 98916

Disponível em: https://www.nucleodoconhecimento.com.br/contabilidade/custos-deimportacao 
adotada foi exploratória, embasada por levantamento bibliográfico acerca do fluxo envolvido. A partir da análise dos resultados constatou-se desconhecimento sobre as particularidades envolvendo o fluxo de importação dentro da zona franca de Manaus e falhas no mapeando dos custos envolvidos, ocasionando dispêndio de recursos e gerando influência direta e significativa no resultado do exercício. Mediante implantação das mudanças propostas, espera-se que os pontos críticos citados sejam mitigados e os impactos no resultado da empresa sejam minimizados, aumentando assim a lucratividade.

Palavras-chave: Processo de importação, Custos, Zona Franca de Manaus.

\section{INTRODUÇÃO}

Com um mercado global em constante mudança, as indústrias estão cada vez mais focadas nos controles dos seus gastos para assim evitar possíveis prejuízos, para as indústrias localizadas na Zona Franca de Manaus, o processo de importação de mercadorias é um dos processos que mais necessitam de atenção para evitar gastos desnecessários.

O presente artigo tem por intuito demonstrar o estudo de caso realizado na empresa $X$, onde se desempenhou análises mediante aplicação de diagnóstico organizacional, apontando que o resultado do exercício possui impactos oriundos dos processos de importação, impactos estes ocasionados pelo desconhecimento dos setores envolvidos, falha no mapeamento dos custos de importação e por falta de suporte adequado por parte da assessoria contratada.

Diante da constatação nos surge a seguinte questão: Qual a influência dos custos de importação no resultado do exercício? O conhecimento e controle dos custos são ferramentas de extrema importância para que se mantenha a competitividade em um mercado cada dia mais exigente. Pois, como cita Martins (2010), os custos servem para indicar os caminhos para empresa e necessitam ser bem geridos para que se obtenha o melhor resultado, devido a relevância do tema, este artigo tem como 
objetivo principal a demonstração da influência dos custos de importação no resultado da instituição.

Adotando uma metodologia baseada em pesquisa bibliográfica, de natureza qualitativa e aplicada e fins descritivos e exploratórios, foi elaborada uma proposta de implementação da ferramenta $5 \mathrm{~W} 2 \mathrm{H}$ em conjunto com a realização de treinamentos para mitigar as perdas financeiras.

O tema viabiliza conhecimento sobre os custos de importação dentro da zona franca de Manaus oferece ainda soluções para o controle destes custos. Organizou-se o artigo em três partes: a primeira apresentando a formulação, problemática e sua justificativa e por fim adentra ao referencial teórico, a segunda contendo a metodologia aplicada acerca do objeto de estudo (Empresa X) e na terceira os resultados obtidos através das técnicas aplicadas de coletas e análise dos dados e por fim estão elencados todas as referências utilizadas como base para o progresso do trabalho.

\section{FUNDAMENTAÇÃO TEÓRICA}

A fundamentação teórica torna-se importante pois, como bem comenta Libório (2015, p. 40), o desenvolvimento em si, onde o autor expõe suas afirmações e de outros, agregado com pesquisas acerca do tema relacionado, promovem discussões segundo perspectivas da própria experiência de trabalho, fazendo com que o usuário desperte o entendimento do assunto abordado.

Vergara (2016) ainda enfatiza que a fundamentação teórica, dentro de um projeto, apresenta pesquisas ou algo que tenha ligação com o tema, que já tenha sido citado ou realizado por outros autores.

Como é a partir da fundamentação teórica que se inicia a pesquisa científica, sua função é resumir informações existentes do modo mais completo possível, fornecendo o devido embasamento ao assunto relatado.

RC: 98916

Disponível em: https://www.nucleodoconhecimento.com.br/contabilidade/custos-deimportacao 
Deste modo realizou-se pesquisa bibliográfica baseando-se em artigos científicos avaliados por conhecedores do assunto, livros, trechos de lei e artigos disponíveis na internet.

\subsection{CONTABILIDADE DE CUSTOS}

Com a evolução das indústrias e a busca constante por melhorias nos processos, a contabilidade adaptou-se para atender a necessidades de apuração dos resultados, adotando quase que de forma natural o modelo de apuração existente nas empresas comerciais de revenda, que compravam mercadorias e revendia a terceiros, modificando o item "compra" pelos fatores envolvidos no processo de aquisição de matéria prima e agregando os demais fatores da atividade industrial, denominandoos assim de "custos de produção".

Viceconti (2013) diz que, o setor que era responsável pelo controle dos gastos foi batizado como "contabilidade de custos" tendo em seus primórdios a principal função de controle dos estoques das indústrias, o que era um procedimento muito complexo naquela época.

Já Osni Ribeiro Moura (2017) diz que, ao se falar de custos industriais não estamos falando apenas de procedimentos contábeis, mas também dos extracontábeis, pois estes são igualmente imprescindíveis ao conhecimento do quanto o produto custou para empresa.

Leone (2010) é enfático ao dizer que este braço da contabilidade, tem um olhar diferenciado quando produz informações, seus critérios de avaliação, cálculo e alocação geram informações claras e diretas em um ambiente em constante mutação.

Crepaldi (2011) complementa dizendo que custos constitui um dos fatores mais importantes dentro da formação do preço de vendas, seja de mercadoria ou de serviços, pois estabelece limites mínimos para o preço. 


\subsection{MODELO ZONA FRANCA DE MANAUS}

De acordo com Bonfim e Botelho (2009), a idealização do modelo da Zona Franca de Manaus surgiu em meados da década de 60, a princípio por meio de projeto geopolítico, objetivando de preservar a soberania nacional da extensa região amazônica. De acordo com Botelho (2010), neste momento, diferentes incentivos que eram destinados aos projetos instalados na região fim de diminuir desvantagens ocasionadas pela localização geográfica, considerada como não interessante pelos empresários.

De acordo com o Decreto lei ํㅜ 288/1967 a Zona Franca de Manaus (ZFM) é uma área de livre comércio, tendo incentivos fiscais distintos de forma a proporcionar o desenvolvimento econômico, afirma ainda em seu artigo 10 que a administração, tanto das instalações quando dos serviços, será desempenhada pela Superintendência da Zona Franca de Manaus (Suframa).Mais tarde o Decreto lei no 356/1968 estenderia benefícios do antigo decreto aos bens que fossem recebidos, beneficiados ou ainda fabricados na área da zona franca de Manaus.

Segundo a Suframa (2019) em meados da década de 90, o Polo Industrial de Manaus (PIM) obteve enorme ascensão e sua estrutura passava a servir como base de sustentação. Como é popularmente conhecido o PIM, possui diversos incentivos, tanto federal quanto estadual, que são administrados por três diferentes entidades.

A Superintendência da Zona Franca de Manaus (Suframa) é responsável por avaliar os processos de importação, podendo conceder suspensão do percentual no Imposto de Importação (II) conforme descreve o art. 3 do Decreto 61.244 de agosto de 1967. (BRASIL, 1967)

A Superintendência do Desenvolvimento da Amazônia, também conhecida como SUDAM, uma autarquia federal responsável pelo desenvolvimento da região que estimula os investimentos por meio o gerenciamento de incentivos e benefícios 
fiscais, como cita o art. 4ํㅜㄹ inciso IX da Lei complementar 124 de janeiro de 2007. (BRASIL, 2007)

Temos ainda a Secretaria da Fazenda (SEFAZ-AM), que segundo o Decreto-Lei № 20.686 de 28 de dezembro de 1999 e o Decreto-Lei № 26.438 de 29 de dezembro de 2006 opera nos assuntos que envolvem ICMS ou Imposto sobre Operações Relativas à Circulação de Mercadorias e sobre Prestações de Serviços de Transporte Interestadual e Intermunicipal e de Comunicação.

\subsection{DEFINIÇÃO DE INDÚSTRIA}

Resumidamente, indústria é o local onde ocorre a transformação de matérias primas em outros objetos (prontos ou não) para consumo, ao longo dos tempos e com o advento de novas tecnologias o conceito vem se expandindo, como Perez (2010) comenta que mudança econômica e inovação industrial trazem sempre novos desafios, definindo novos comportamentos dentro das organizações.

Indústrias podem ser classificadas de diversas formas, de acordo com sua finalidade (bens de produção, bens de capital, bens de consumo), com base na sua atividade econômica (extrativista, transformação) ou ainda levando em consideração o seu setor de atuação (energética, alimentícia, construção civil, bélica) mas independente de sua classificação, em algum momento podem necessitar do mercado externo para atender suas necessidades.

\subsection{CONCEITO DE IMPORTAÇÃO}

Robles e Nobre (2016) dizem que o comércio exterior corresponde ao conjunto de exportações e importações entre países, onde termo "importação" define basicamente, compras internacionais, realizadas ou não por uma pessoa jurídica.

Este processo vem sendo ampliado gradativamente com a competitividade do mercado no cenário atual com a grande escassez e baixa qualidade de alguns 
insumos no mercado interno, o que faz com que as indústrias busquem trazer esses insumos necessários de outros países.

O que corrobora com o descrito por Keedi (2012) que afirma que importar é adquirir do estrangeiro mercadorias de interesse próprio, ou úteis para determinado público e ao seu desenvolvimento, ou seja, a compra de bens fabricados no exterior ou mesmo como mencionado por Vieira (2010) é o ato de inserir no país produtos ou serviços advindos do exterior.

Importar pode ser apropriado visto que permite ao país cliente a aquisição de um produto ou serviço de alta tecnologia, conseguida por intermédio de pesquisas e de muitos anos de vivência (EIDELCHTEIN et al., 2010).

\subsection{PROCESSO DE IMPORTAÇÃO NA ZONA FRANCA DE MANAUS - ZFM}

Devido necessidades impostas pelo mercado cada dia mais exigente e a escassez de insumos com a qualidade que os clientes buscam, a importação tornou-se uma opção cada dia mais procurada por indústrias nacionais.

Sousa (2009) afirma que a importação ocorre sempre que um bem adentra um país, no entanto quando se fala de zona franca de Manaus, não é simples e rápido como se pensa, deve-se observar as etapas e legislações necessárias caso se pretenda ter um processo sem complicações.

Ao se importar dentro da ZFM as indústrias buscam o que está descrito no art. 505 do Regime Aduaneiro (RA), quando se diz que, ao ocorrer a entrada de mercadorias oriundas de nacionalidade estrangeira nos domínios da zona franca, sendo elas direcionadas para industrialização ou consumo interno em qualquer grau, incluindo beneficiamento, pesca, agropecuária ou ainda instalação, operação e estocagem para posterior reexportação, esta será isenta dos impostos de importação.

RC: 98916

Disponível em: https://www.nucleodoconhecimento.com.br/contabilidade/custos-deimportacao 
Devido os dispositivos legais é a forma mais aplicada de importação, dada a isenção do imposto de importação, o que contribui com a receita da empresa, quando se fala em mercadorias nacionais, observa-se também o art. 506 do Regime Aduaneiro que diz que, mercadoria de origem nacional, sendo elas para industrialização ou consumo direto, no território da Zona Franca de Manaus, fiscalmente terão efeito de uma exportação.

Há ainda um fluxo interno a ser seguido caso queira o processo transcorra com normalidade, onde deve-se observar cada etapa, suas necessidades e particularidades e as informações importantes como por exemplo o "canal de liberação", atribuído pelos SISCOMEX depois do processo de registro da declaração de importação.

Figura 1 - Fluxo do processo de impostação na zona franca de Manaus.

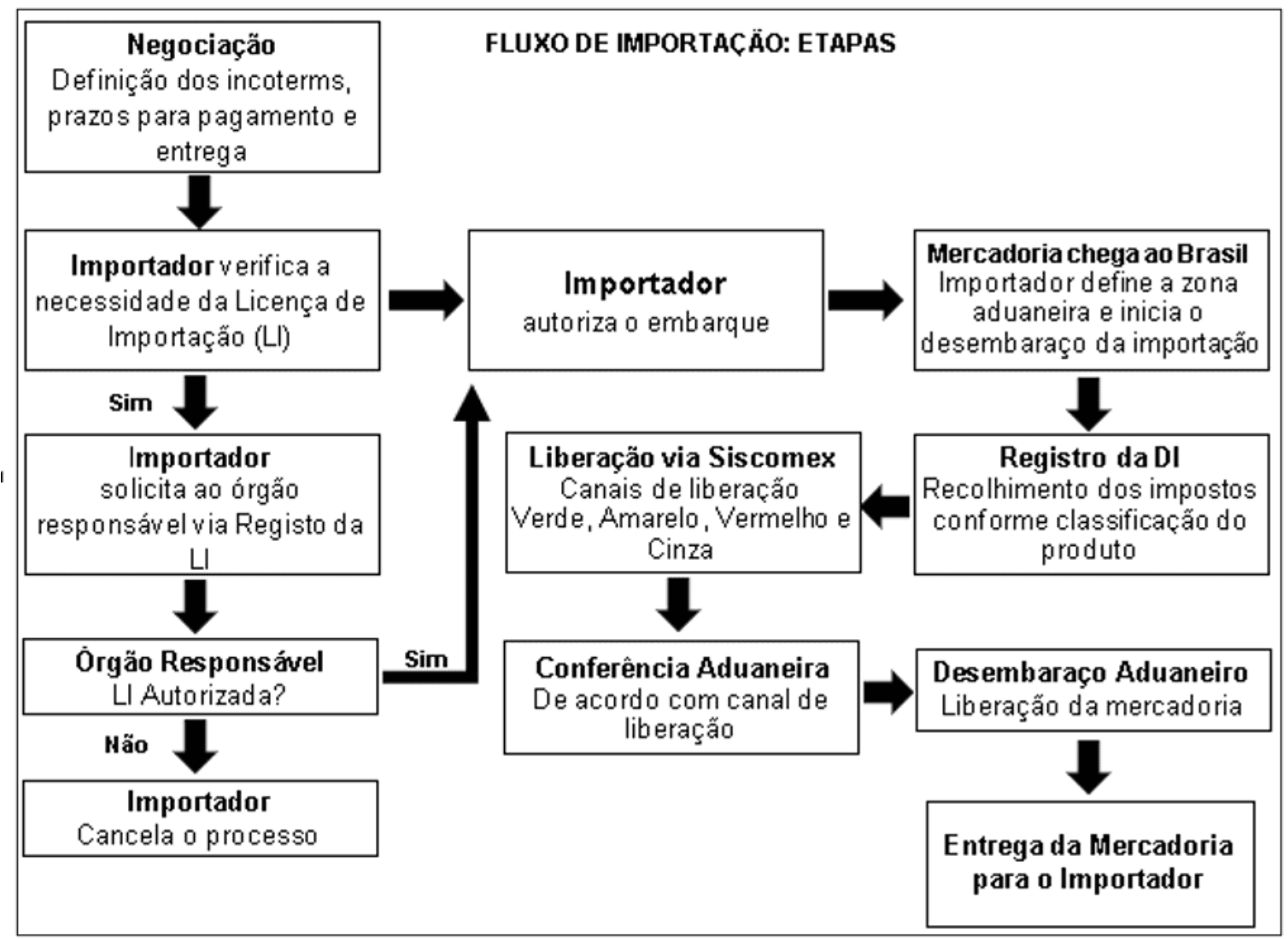

Fonte: Elaborado pelos autores e amparado por pesquisas.

RC: 98916

Disponível em: https://www.nucleodoconhecimento.com.br/contabilidade/custos-deimportacao 
Figura 2 - Canais de liberação SISCOMEX

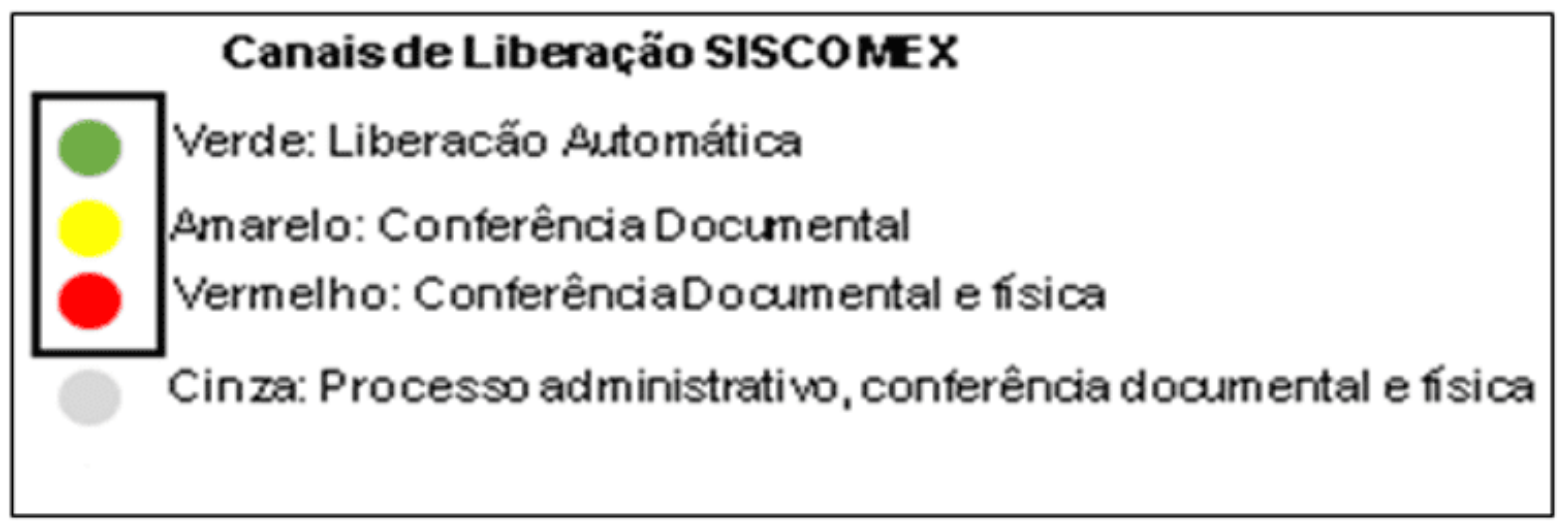

Fonte: Elaborado pelos autores e amparado por pesquisas.

\subsubsection{DOCUMENTOS DE IMPORTAÇÃO}

O país precisa ter controle do que entra e sai, assim a Receita Federal do Brasil (RFB) orienta em seu Manual de Importação que antes do processo de despacho da importação, o dito como importador, deverá se habilitar na operação do Sistema Integrado de Comércio Exterior, o SISCOMEX (RECEITA FEDERAL DO BRASIL, 2019).

Conforme descreve o art. 20 do Decreto-Lei № 6.759 de 5 de fevereiro de 2009, os documentos que sejam considerados necessários tanto para instrução quanto para controle da aduana, pode ser transmitido eletronicamente pela RFB e devem ser mantidos tanto pelo importador quanto pelo exportador pelo período mínimo obrigatório, dentre eles estão correspondências comerciais, os documentos de negociação e cotação de preços, contrato comercial, financeiro e/ou cambial, transporte e de seguro das mercadorias, além dos os registros contábeis e documentos fiscais correspondentes. (BRASIL, 2009)

A RFB elenca como documentos do processo de despacho de importação: Conhecimento de Carga, Fatura Comercial, Romaneio de Carga ou Packing-List, Prova de Origem e Manifesto de Carga (MANUAIS ADUANEIROS, RFB, 2014).

RC: 98916

Disponível em: https://www.nucleodoconhecimento.com.br/contabilidade/custos-deimportacao 
E quando preciso ou solicitado há também o registo da $\mathrm{LI}$ ou Licenciamento de importação, que determina características da mercadoria conforme pede a Portaria SECEX n. 23, de 2011 emitido pelo governo federal.

\subsubsection{RELAÇÃO DOS INCOTERMS (INTERNATIONAL COMMERCIAL TERMS / TERMOS INTERNACIONAIS DE COMÉRCIO)}

O comércio exterior avançou e com isso tornou-se necessário sua regularização, de modo que foi necessário a Câmara de Comércio Internacional propor termos internacionais para as relações de comércio, com o intuito de facilitar as relações entre compradores e vendedores de nacionalidades diferentes (INTERSABERES, 2014, p.96).

Utilizado nos contratos de compra e venda internacionais, o "incoterms" ou International Commercial Terms, nada mais são que os termos definidores de responsabilidades, tanto do exportador como do importador, objetivando a promoção do equilíbrio nas relações comerciais internacionais" (LUNARDI, 2011, p. 27) ou como descrito ainda por Queiroz; Aprigio (2013, p.12) padroniza e define regras de onde o exportador deve entregar, quem paga o frete e quem contrata o seguro.

A correta escolha do tipo de Incoterms é importante, pois pode interferir diretamente na relação custo-benefício. Abaixo estão apresentadas as principais relações dos incoterms, bem como as características de cada modalidade comercial.

Quadro 1 - Relações Incoterms

\begin{tabular}{|l|l|l|}
\hline Sigla & Significado & Características \\
\hline EXW & Ex Works & $\begin{array}{l}\text { Quem vende disponibiliza a mercadoria na sua } \\
\text { empresa, porém quem compra é que arca com os } \\
\text { custos da operação. }\end{array}$ \\
\hline FCA & Free Carrier & $\begin{array}{l}\text { Quem vende se responsabiliza pelos custos até o } \\
\text { transportador, isso com a mercadoria já }\end{array}$
\end{tabular}




\begin{tabular}{|l|l|l|l|}
\hline FAS & Free Alongside & $\begin{array}{l}\text { desembaraçada. } \\
\text { Quem vende é responsável pelos custos até que a } \\
\text { mercadoria esteja ao lado do navio desembaraçada } \\
\text { para exportação. }\end{array}$ \\
\hline FOB & Free on Board & $\begin{array}{l}\text { Quem vende arca com os custos até que a mercadoria } \\
\text { esteja a bordo do navio. }\end{array}$ \\
\hline CFR & Cost and Freight & $\begin{array}{l}\text { Quem vende entrega a mercadoria a bordo do navio e } \\
\text { se responsabiliza pelo frete até o porto de destino. }\end{array}$ \\
\hline CPT & Carriage Paid To & $\begin{array}{l}\text { Quem vende entrega a mercadoria ao transportador e } \\
\text { é responsável pelo transporte até o local o destino. }\end{array}$ \\
\hline CIF & $\begin{array}{l}\text { Cost, Insurance } \\
\text { and Freight }\end{array}$ & $\begin{array}{l}\text { Quem vende entrega a mercadoria a bordo do navio e } \\
\text { se responsabiliza pelo frete e o seguro até o porto de } \\
\text { destino. }\end{array}$ \\
\hline CIP & $\begin{array}{l}\text { Carriage } \\
\text { Insurance Paid To }\end{array}$ & $\begin{array}{l}\text { Quem vende entrega a mercadoria ao transportador e } \\
\text { se responsabiliza pelo frete e o seguro até o local de } \\
\text { destino. }\end{array}$ \\
\hline DAT & $\begin{array}{l}\text { Delivered } \\
\text { terminal }\end{array}$ & $\begin{array}{l}\text { at } \\
\text { Quem vende deve entregar a mercadoria no terminal } \\
\text { ou porto, descarregados. }\end{array}$ \\
\hline DAP & $\begin{array}{l}\text { Delivered at Place } \\
\text { Quem vende entrega a mercadoria no local acordado, } \\
\text { prontos para serem descarregados. }\end{array}$ \\
\hline Delivered & Duty & $\begin{array}{l}\text { Quem vende entrega a mercadorias no local acordado, } \\
\text { prontos para serem descarregados, com os devidos } \\
\text { desembaraços de importação e com os direitos de } \\
\text { importação pagos. }\end{array}$ \\
\hline
\end{tabular}

Fonte: Elaborado pelos autores e amparado por pesquisas

Maia (2013) enfatiza que os Incoterms são definidores do início e o fim das responsabilidades entre o vendedor e o comprador, desta forma auxilia gestão de possíveis conflitos oriundos dessas responsabilidades, sendo elas ou não intencionais, o que pode vir a prejudicar a relação de negócios. 


\subsubsection{INFORMAÇÕES DO INVOICE}

Documento que dá origem ao contrato de compra e venda internacional é base para o desembaraço alfandegário, e é tão importante que, o RA art. 553 inciso II, diz que a via original deve ser assinada pelo exportador e cada emenda ou ressalva deve ser autenticadas por ele.

Conforme disposto no artigo 557 do regime aduaneiro, devem constar na Invoice as seguintes informações:

Quadro 2 - Informações do Invoice.

Dados completos do importador, como Nome ou razão social e localização;

Detalhes técnicos da mercadoria em idioma nativo ou oficial, seguindo o Acordo Geral sobre Tarifas e Comércio, indicando elementos indispensáveis à que seja realizada seu reconhecimento;

Se houver, devem constar marcas e ou numeração dos volumes;

quantia e tipos dos volumes;

peso bruto, levando em consideração embalagens;

peso líquido, com as mesmas considerações;

país onde foi produzida a mercadoria ou onde ocorreu a última transformação relevante;

país onde foi realizada a aquisição, local de onde será exportada para o Brasil. país procedente ou local onde se encontrava a mercadoria no ato da aquisição;

valores unitário e total por mercadoria e, se houver descontos concedidos, seus totais e natureza.

frete e outras despesas inerentes às mercadorias;

moeda e condições de pagamento; e

modalidade INCOTERMS.

Fonte: Elaborado pelos autores

RC: 98916

Disponível em: https://www.nucleodoconhecimento.com.br/contabilidade/custos-deimportacao 
É um documento tão importante que a Declaração de Importação (DI) será formada com base na via original da fatura comercial, devidamente assinada pelo exportador ou seu representante legal e caso não se apresente como solicitado o processo de despacho será interrompido como disposto no art. 570, § 1ํㅜㄹ inciso I, do Regulamento Aduaneiro.

\subsubsection{CARACTERÍSTICAS DO VALOR DECLARADO}

No âmbito da contabilidade de custos, uma informação de extrema importância constante no invoice é o valor declarado da mercadoria, isso se deve ao fato que este valor terá duas finalidades, um para tributação e outro para cálculo de variação cambial. Na parte de tributos, os valores declarados devem corresponder ao real valor do produto, onde ainda que haja desconto concedido ou mesmo doação, devese informar o valor real. Já o valor para cálculo de variação cambial, este poderá ser o valor "negociado" com os devidos descontos concedidos ou mesmo doações.

ludícibus et al. (2013) diz que para que os componentes do custo, independente do produto, sejam definidos, vários aspectos devem ser levados em consideração, inicialmente deve-se analisar o que está discriminado na documentação de compra. Definição de custo de aquisição engloba o preço do produto adquirido, somando-se os custos adicionais, até que este produto esteja disponível nos domínios da empresa.

\subsection{CUSTOS DE IMPORTAÇÃO}

A formação do custo no processo de importação envolve fatores que não são controlados ou ainda desconhecidos pela empresa. Vieira (2010, p. 155) afirma que, antes de dar início a qualquer negociação internacional, é muito importante que qualquer empresa faça um planejamento claro e objetivo e devem analisar tendências, tecnologia, assistência técnica, idoneidade do fornecedor e a pontualidade da entrega. 
A matéria "Análise dos Custos de Importação", publicada pelo site BRTRADING (2020) classifica os custos de importação em três grupos: Custos Comerciais, Custos Operacionais e Custos Aduaneiros e Tributários.

Nos custos comerciais temos o valor negociado e custos com instituições financeiras que vão realizar o pagamento no exterior.

Os custos operacionais sofrem grande influência do Incoterms, o modo que a mercadoria ou produto será embarcado (aéreo, marítimo, terrestre) e de especificações do produto (peso, volume, frágil).

Quanto aos custos aduaneiros e tributários estão os impostos de importação (II), imposto sobre produto industrializado (IPI), PIS, COFINS e taxa de utilização do SISCOMEX, sem esquecer do ICMS, AFRMM (Adicional de Frete para Renovação da Marinha Mercante) caso venha no marítimo.

O total dos custos do processo é a soma dos valores pagos ao fornecedor pela mercadoria somando o frete internacional, seguros, tributos e taxas e demais despesas relacionadas. Do montante total devem ser reduzidos os tributos recuperáveis e o unitário consegue-se realizando a divisão do montante total do processo pela quantidade total envolvida.

\subsubsection{LOGÍSTICA}

O termo "logística" é comumente ligado ao transporte, no entanto a palavra em si é muito mais abrangente, Silva (2012) diz que logística engloba o planejamento, a implementação e controle eficiente e a eficiência do fluxo e armazenagem de produtos, deste a sua origem até o ponto onde será consumido, sempre visando atender o cliente.

Dentre os custos em um processo de importação, o logístico é um dos mais importantes pois, grande parte do processo depende desse aspecto. Dentre o que pode ser gerenciado pela logística estão itens físicos como gêneros alimentícios, 
materiais diversos, animais, máquinas e equipamentos, e os abstratos, como quando se fala em gerenciamento de tempo e distância, envolvendo ainda armazenagem e transporte de produtos até o consumidor final.

Oliveira (2014) diz que, para os administradores a distância envolvida em um processo de importação gera incertezas pois há demandas que necessitam de urgência, e as vezes negociações são adiadas ou acabam não se realizando devido à diferença de horário.

Gerenciar de forma correta as operações da logística, segundo Reis (2015), é essencial para que haja redução das perdas e as entidades possam assim se manter competitivas no mercado globalizado.

\subsubsection{OPERACIONAIS}

Os custos operacionais em um processo de importação podem começar ainda no exterior, quando o Incoterms determinar que o responsável pela compra é quem arca com os custos da operação.

Um dos custos mais relevantes em qualquer operação de longa distância, seja ela de importação ou mesmo no mercado interno, tirando o custo da mercadoria, é sem dúvida o custo do frete, isso é ocasionado devido a falta de infraestrutura tanto portuária quanto rodoviária no país.

Brandão (2009) afirma que, os custos portuários, o lead time e a disponibilidade de armadores para determinadas regiões ou rotas aumentam e muito o custo do frete internacional.

Impostos e taxas são outros custos que agregam a operação e ocorrem em todas as etapas, além destes temos o Adicional ao Frete para Renovação da Marinha Mercante (AFRMM) que incide sobre algumas situações e que está disposto no Decreto-lei no 2.404/1987 e disciplinado pela Lei no 10.893/2004, em algumas 
situações pode chegar a $40 \%$ sobre o valor do transporte, onerando ainda mais o custo da operação.

\subsubsection{SEGURO}

O código civil em seu artigo 757 diz que a celebração do contrato de seguro, o obriga o segurador a pagar algo chamado de prêmio, garantindo ao segurado reembolso do devido bem ou coisa, contra o que for determinado previamente no contrato, ou seja, é um documento onde uma parte (segurador) se obriga com outra (segurado) a pagar um prêmio caso ocorra prejuízo, conforme previso em contrato.

Em um processo de importação essa obrigação do seguro é definida no Incoterms e não são os valores mais expressivos, no entanto, são muito importantes para que se haja uma segurança da mercadoria no trajeto, além de serem considerados na composição do valor aduaneiro da mercadoria como disposto no Decreto № 6.759/2009 em seu artigo 77, inciso III.

Segundo Gabriel Segalis (2015) os termos mais comuns nos contratos de seguros internacionais são: segurado, valor do segurado, bem segurado, beneficiário, sinistro, valor da indenização e risco.

\subsubsection{TAXAS}

Estarão presentes em praticamente toda etapa do processo de importação, principalmente quando iniciar o processo de registro da importação, Tavares (2009) comenta que diferente dos impostos, os fatos geradores das taxas estão diretamente ligados a uma estatal específica, o Código Tributário Nacional, em seu artigo 77 diz que quem pode cobrar taxas são a União, os Estados, os Municípios e o Distrito Federal, isto dentro do que lhe for de responsabilidade, tendo este o poder de polícia.

Sobre as importações dentro da área da zona franca de Manaus as principais são a TUS (Taxa de Utilização do SISCOMEX), a AFRMM (Adicional de Frete para

RC: 98916

Disponível em: https://www.nucleodoconhecimento.com.br/contabilidade/custos-deimportacao 
Renovação da Marinha Mercante) que foi instituída pela Lei $n^{0} 10.893 / 2004$, e recentemente institui-se a TCIF (Taxa de Controle de Incentivos Fiscais) e a TS (Taxa de Serviços).

\subsubsection{IMPOSTOS}

É uma espécie tributária da alçada da União, Estados, Distrito Federal e Municípios e está descrito nos artigos 153, 155 e 156 da CRFB/1988 e que de acordo com o Código Tributário Nacional em seu artigo 16 é a obrigação gerada por uma situação que não dependa de qualquer operação estatal específica, relacionada ao contribuinte.

Tavares (2009, p. 76) completa dizendo que a entidade tributante não é obrigada a oferecer qualquer benefício direto ou mesmo vantagem para quem o paga.

O fato gerador do imposto não está diretamente ligado a nenhuma atividade estatal, constata-se então, que é um tributo de caráter comum e obrigatório, que é independente de qualquer serviço ou atividade do poder público em relação ao contribuinte.

\subsection{DEMONSTRATIVOS OPERACIONAIS E FINANCEIROS}

Os demonstrativos operacionais e financeiros são a porta de entrada para investidores (em caso de empresas de capital aberto) e ponto de intensa avaliação para os acionistas, a Comissão de Valores Mobiliários corrobora quando afirma que as análises de informações contábeis e financeiras são o marco zero para que se conheça a instituição.

Marion (2010) aprofunda dizendo que a avaliação das demonstrações apresentadas pela contabilidade gerencial de uma instituição sem foram e continuarão sendo um eixo fundamental. Os principais investidores colocam o balanço patrimonial e a demonstração de resultado como sendo os principais demonstrativos operacionais e 
financeiros de uma empresa, pois é a partir deles que os índices necessários são extraídos.

Lagioia (2011) diz que indicadores baseados nas demonstrações financeiras são de deveras importante, dão solidez à decisão do investidor, Veiga (2011) complementa dizendo que são de grande importância, tanto gerencial quanto administrativa, pois repassa com grande clareza todas as operações que envolvem receitas, custos e despesas, e também a relevância dos tributos.

Veiga (2011) ainda diz que por meio de análises verticais torna-se possível avaliar fatos importantes como os custos em relação às vendas e acompanhar mensalmente se houve variações significativas.

\section{MATERIAIS E MÉTODOS}

Os materiais e métodos desenvolvidos nesta pesquisa basearam-se no estudo de caso realizado na empresa $X$, onde informações foram coletadas e analisadas visando aprimorar a metodologia aplicada.

Japiassú (2013) é claro ao dizer que, este item do trabalho será lido frequentemente, assim o pesquisador precisa usá-lo para evidenciar suas conquistas alcançadas e fazendo menção ao proposto nos objetivos gerais.

Trigueiro (2014, p. 30) é categórico ao dizer que a metodologia difere em seus significados, podendo assim, ser empregada com contextos diferentes. Para alcançar o objetivo do estudo, pode-se utilizar métodos e técnicas que melhor se adequem à pesquisa.

\subsection{PROCEDIMENTOS METODOLÓGICOS}

A presente estudo constituiu-se por meio de uma pesquisa bibliográfica, com coleta de dados em uma determinada organização, objetivando gerar conhecimento acerca do tema abordado, constituiu-se o embasamento teórico necessário devidamente 
amparado em artigos, documentos, livros e dissertações que possibilitaram as análises, interpretações e conclusões.

\subsubsection{QUANTO À NATUREZA}

Quanto a natureza, elaborou-se uma pesquisa aplicada, com abordagem qualitativa, pois "dedica-se a agregar conhecimento, buscando também elucidar problemas específicos além de revelar a verdade para uma determinada utilidade prática" (THESAURUS, 2016), e baseou-se em dados coletados com intuito de desenvolver ferramentas para solucionar a problemática identificada na organização.

\subsubsection{QUANTO AOS FINS}

Quanto aos fins, trata-se de uma pesquisa descritiva e exploratória pois, como citado por Vergara (2016, p. 74), "visa expor particularidades de certa população ou de um fenômeno determinado". Podendo ainda estabelecer ligações entre variáveis definindo assim sua natureza, sem o compromisso de elucidar os fenômenos que relata, ainda que sirva de suporte para tal explicação.

\subsubsection{QUANTO AOS MEIOS}

Quanto aos meios, adotou-se um estudo de caso para tornar as informações da pesquisa bibliográfica mais perceptível, obtendo suporte do embasamento teórico, o que a torna interessante e ajuda tanto o estudante quanto o autor, interessado em tirar proveito desta metodologia, isto caso se faça uma descrição e uma análise do caso o mais detalhado possível, e com o devido embasamento teórico, como mencionado por Pereira (2018, p. 74).

\subsection{CARACTERIZAÇÕES DA EMPRESA X}

A empresa $X$, atuante sob o regime tributário de lucro real, está situada no distrito industrial, na cidade de Manaus, atuante desde 2003 no segmento de resinas termoplásticas, como o poliestireno de alto impacto, com larga aplicação na indústria

RC: 98916

Disponível em: https://www.nucleodoconhecimento.com.br/contabilidade/custos-deimportacao 
de móveis, eletrodomésticos, eletrônicos e descartáveis, e desde 2013 no segmento de filmes de polipropileno biorientado, conhecido como BOPP, além de tampas plásticas e laminados com ampla aplicação em embalagens plásticas alimentícias.

Com o portfólio atual, a empresa é uma das fornecedoras de grandes empresas como Whirlpool, 3M, Ambev, Coca Cola entre outras, destacando-se pela qualidade dos seus produtos possuindo duas unidades em Manaus e uma no sul do país, além da sua sede administrativa em São Paulo, sempre prezando pela qualidade e satisfação dos seus clientes.

\section{RESULTADOS E DISCUSSÕES}

De acordo com o proposto por Austin (2013) é fundamental a realização do diagnóstico de desempenho de uma empresa, visto que agiliza o processo de tomadas de decisões dentro da organização, servindo ainda como uma ferramenta que proporciona um panorama geral e dinâmico de cada nível da organização.

O presente estudo de caso, realizado na empresa $X$, constatou na fase de diagnóstico organizacional, mediante coleta e análise de dados no sistema ERP SAP, impactos relevantes dos custos de importação no resultado do exercício.

\subsection{GRÁFICO DAS PRINCIPAIS RELEVÂNCIAS NO PROCESSO DE IMPORTAÇÃO}

Baseado nos pontos críticos identificados na fase de diagnostico organizacional coletou-se mais informações no sistema ERP SAP acerca dos processos de importação, onde foi possível identificar pontos críticos que estão causando relevantes impactos conforme disposto no gráfico 1. 
Gráfico 1 - Influência dos custos no processo de importação

\section{Impacto no Processo de Importação}

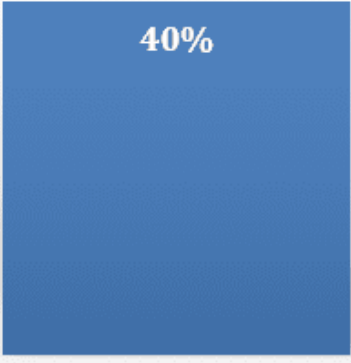

Falha no processo de importação

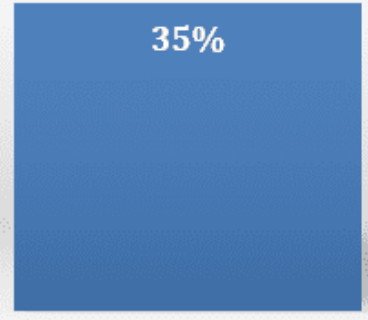

Reajuste de preços

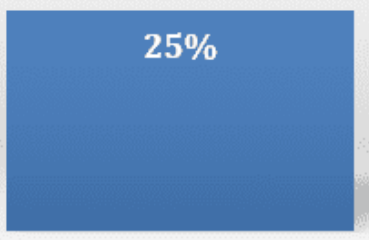

Variação Cambial

Fonte: elaborado pelos autores com base no diagnóstico da empresa $X$.

O gráfico de diagnóstico dos pontos de influência nos processos de importação aponta que, dos custos mapeados, cerca de $40 \%$ foram gerados devido a falhas no decorrer do processo. Como não há ação por parte da organização quanto a variação cambial e já há política de cotações para controle dos preços, traçou-se propostas de melhorias visando mitigar as falhas identificadas e assim reduzir custos.

Uma das melhorias propostas é a implantação da ferramenta $5 \mathrm{~W} 2 \mathrm{H}$ que segundo Polacinski (2012) consiste na aplicação de um plano de ação com atividades prédefinidas que necessariamente devem ser efetivadas com clareza, funcionando também como um mapeamento, onde o objetivo é responder a sete questões.

\subsection{DESCONHECIMENTO DA LEGISLAÇÃO INTERNA DA ZONA FRANCA DE MANAUS - ZFM}

A instituição possui um setor responsável pela gestão de importações dentro da zona franca de Manaus localizado no estado de São Paulo e com alta rotatividade de colaboradores, a maioria destes colaboradores não passou ou possui nenhum 
treinamento ou conhecimento mais aprofundado acerca da legislação da zona franca de Manaus, o que por sua vez pode acarretar prejuízos financeiros.

Estabeleceu-se como proposta, para mitigação deste ponto crítico, a criação e aplicação de uma política de treinamentos que, segundo estudo realizado por Guimarães e Pimenta (2020), em face as crises econômicas mundiais constantes, a utilização de treinamentos como ferramenta de gestão tornou-se imprescindível dentro das empresas, pois capacita os funcionários e promove a competência profissional para exercer as atividades praticadas.

O treinamento será ministrado pelo gerente do setor fiscal/tributário junto aos colaboradores dos setores de suprimentos e logística do escritório de São Paulo, que são os responsáveis pelo processo de importação, sendo desenvolvido 100\% online via plataforma digital, sem custos adicionais, devido ser efetuado por colaboradores internos.

A base do treinamento como proposto será suporte da ferramenta $5 \mathrm{~W} 2 \mathrm{H}$, a medida visa verificar a eficácia do treinamento e da aplicação da ferramenta no ambiente organizacional, conforme disposto no quadro 3.

Quadro 3 - Aplicação da ferramenta $5 \mathrm{~W} 2 \mathrm{H}$ para realização de treinamento fiscal/tributário.

\section{Treinamento Fiscal/Tributário}

O que? Treinamento dos colaboradores para conhecimento e entendimento do processo de importação da zona franca de Manaus.

Por quê? Necessidade de conhecimento sobre o processo de importação para melhor execução de atividades como: classificação de NCM e destinação de mercadorias

Onde? Treinamento realizado nas dependências da própria empresa

Quando? Cronograma a ser definido com base na confecção do material e disponibilidade da gerência tributária, prazo máximo último trimestre de 
2021.

Quem? Gerente Fiscal/Tributário

Como? Treinamento será realizado na plataforma Teams objetivando apresentar as legislações pertinentes ao processo de importação, o fluxo de liberação de mercadoria, modais logísticos e tributações.

Quanto? Sem custos adicionais.

Fonte: Elaborado pelos autores com base no diagnóstico da empresa $X$.

\subsection{FALHA NO MAPEAMENTO DOS CUSTOS DE IMPORTAÇÃO}

A falta deste conhecimento sobre as obrigatoriedades envolvidas no processo de importação da zona franca de Manaus causa falhas no processo de mapeamento dos custos, além disto a distância e desconhecimento também do processo logístico, geram ainda mais despesas.

Neste ponto espera-se que a aplicação da ferramenta $5 \mathrm{~W} 2 \mathrm{H}$ juntamente com o treinamento acerca da legislação e fluxos de importação possa servir como forma de prevenir novas falhas.

\subsection{CONTRATAÇÃO DE ASSESSORIA ESPECIALIZADA}

Há uma empresa terceirizada contratada para realização do serviço de despacho aduaneiro, no entanto a empresa não tem o know how e expertise, outro ponto é que falta de um colaborador local acaba por dificultar a comunicação e atrapalhar o processo de tomada de decisão, muitas das decisões acerca do processo logístico são tomadas pela empresa terceirizada sem a anuência do setor responsável gerando despesas desnecessárias.

Para sanar este ponto propôs-se levantamento e possível contratação de um colaborador local com conhecimento e expertise para acompanhar os processos, além de contratação de assessoria especializada em processos de importação para atuar junto ao novo colaborador.

RC: 98916

Disponível em: https://www.nucleodoconhecimento.com.br/contabilidade/custos-deimportacao 


\subsection{O EFEITO DOS CUSTOS DE IMPORTAÇÃO NO ESTOQUE}

O método de custeio adotado pela empresa para controle dos seus estoques é do custo médio ponderado, obtido pela divisão do valor total do estoque pela quantidade de itens, a cada nova entrada temos um novo médio, e este novo custo é utilizado para determinação do CPV ou custo do produto vendido, sempre que ocorre uma venda.

As falhas ocorridas no decorrer do processo acabam onerando o custo final da importação e para fins de composição do valor a ser agregado ao estoque o CPC 16 diz em seu item 11 que o custo de aquisição do estoque é constituído do preço da aquisição, os impostos e despesas (exceto impostos recuperáveis junto ao fisco) e ainda somando os custos com transporte, seguro, manuseios e deduzindo os descontos comerciais e abatimentos. Temos no quadro 4 a composição das despesas de um embarque de matéria prima da empresa X.

Quadro 4 - Levantamento das despesas de um processo de importação

\begin{tabular}{|l|r|}
\hline Despesa & $\mathrm{R} \$$ total \\
\hline FOB & $1.368 .694,62$ \\
\hline Seguro internacional & 301,10 \\
\hline Frete internacional & $342.142,92$ \\
\hline Taxa SISCOMEX & 214,50 \\
\hline AFRMM & $37.171,31$ \\
\hline Taxa de armazenagem & $8.114,19$ \\
\hline Taxa de capatazia & $7.650,00$ \\
\hline Internamento Suframa & 885,00 \\
\hline Despachante aduaneiro & 326,70 \\
\hline Seguro armazenagem & 174,78 \\
\hline Serviços portuários & $3.825,04$ \\
\hline Frete interno & $4.982,18$ \\
\hline
\end{tabular}

RC: 98916

Disponível em: https://www.nucleodoconhecimento.com.br/contabilidade/custos-deimportacao 


\section{Taxa de liberação AWB/BL $\quad 500,00$ \\ S/I \\ Outras despesas \\ Total do embarque \\ $3.343,84$ \\ $1.778 .326,18$}

Fonte: Elaborado pelos autores com base no diagnóstico da empresa $X$.

A análise realizada nos processos de importação, na fase de diagnóstico da empresa $X$, detectaram impactos relevantes no custo final da mercadoria agregada ao estoque. $O$ quadro 5 apresenta a diferença entre o custo projetado e o custo real.

Quadro 5 - Impacto dos custos extras no estoque da empresa X.

\begin{tabular}{|l|c|l|l|}
\hline Projeção & \multicolumn{3}{|l|}{} \\
\hline Matéria Prima A & Quantidade (Kg) & $\mathbf{R}$ unitário & $\mathbf{R}$ total \\
\hline Estoque Inicial & $78.000,000$ & 6,50 & $507.000,00$ \\
\hline Entrada & $229.500,000$ & 7,00 & $1.606 .500,00$ \\
\hline Estoque Reavaliado & $307.500,000$ & 6,87 & $2.113 .500,00$ \\
\hline Realizado & & & \\
\hline Matéria Prima A & Quantidade (Kg) & $\mathbf{R \$}$ unitário & $\mathbf{R}$ total \\
\hline Estoque Inicial & $78.000,000$ & 6,50 & $507.000,00$ \\
\hline Entrada & $229.500,000$ & 7,75 & $1.778 .326,19$ \\
\hline Estoque Reavaliado & $307.500,000$ & 7,43 & $2.285 .326,19$ \\
\hline
\end{tabular}

Fonte: Elaborado pelos autores

Os custos extras não mapeados pela equipe responsável pelos processos de importação foram agregados ao estoque e consequentemente não foram considerados na projeção realizada pela equipe técnica responsável pela formação de preço de venda, o impacto no custo da matéria prima no estoque foi de cerca de $R \$ 0,56$ por quilo, o que totaliza $R \$ 171.826,19$ no total. 


\subsection{IMPACTO DOS CUSTOS NO RESULTADO}

A equipe comercial adotou o preço informado pela equipe responsável pela formação do preço de vendas, estipulando o valor mínimo de venda em $\mathrm{R} \$ 10,00$ por quilo, nas projeções os custos envolvidos no processo seriam de cerca de $R \$$ 6,87 por quilo produzido, no entanto, com os custos extras incorridos no processo de importação e o impacto de $R \$ 0,56$ por quilo o custo de produção final ficou em $R \$$ 7,43 (levando em consideração apenas as matérias primas envolvidas).

O plano de vendas realizado foi de 4.177 toneladas vendidas ao custo de $R \$ 10,00$, no resultado final a diferença de $\mathrm{R} \$ 0,56$ fora do planejamento de preço causou ao resultado uma redução de $\mathrm{R} \$ 2.339 .120$ em relação ao que foi planejado.

Quadro 6 - Influência dos custos de importação no resultado da empresa X.

\begin{tabular}{|l|l|l|}
\hline Demonstração de Resultado & Plano & Realizado \\
\hline Quantidade líquida em quilos & 4.177 .000 & 4.177 .000 \\
\hline Receita Bruta & $\mathbf{4 1 . 7 7 0 . 0 0 0}$ & $\mathbf{4 1 . 7 7 0 . 0 0 0}$ \\
\hline (-) Devoluções & $(871.000)$ & $(871.000)$ \\
\hline (-) Impostos sobre vendas & $(8.833 .200)$ & $(8.833 .200)$ \\
\hline (=) Receita Operacional Líquidas & $\mathbf{3 2 . 0 6 5 . 8 0 0}$ & $\mathbf{3 2 . 0 6 5 . 8 0 0}$ \\
\hline (-) Custo do Material Vendido & $(28.695 .990)$ & $(31.035 .110)$ \\
\hline (=) Lucro Bruto & $\mathbf{3 . 3 6 9 . 8 1 0}$ & $\mathbf{1 . 0 3 0 . 6 9 0}$ \\
\hline (-) Despesas Operacionais & $\mathbf{( 8 9 . 0 7 0 )}$ & $\mathbf{( 8 9 . 0 7 0 )}$ \\
\hline (-) Despesas de Fabricação & $(27.732)$ & $(27.732)$ \\
\hline (-) Despesas Administrativas & $(11.188)$ & $(11.188)$ \\
\hline (-) Despesas Comerciais & $(50.150)$ & $(50.150)$ \\
\hline Resultado antes do IRPJ e CSLL & $\mathbf{3 . 2 8 0 . 7 4 0}$ & $\mathbf{9 4 1 . 6 2 0}$ \\
\hline Valores em reais (R\$) & & \\
\hline
\end{tabular}

Fonte: Elaborado pelos autores. 
No resultado acima demonstrado identifica-se o impacto dos de importação no custo do estoque devido gastos não mapeados no processo de importação, conforme anteriormente demonstrado no quadro 5 , e torna evidente sua influência no resultado final da empresa $X$.

\section{CONSIDERAÇÕES FINAIS}

As importações são uma realidade constante para as indústrias situadas na área da zona franca de Manaus, isso é ocasionado pela escassez do mercado interno para alguns insumos e devido a busca constante de qualidade nos produtos e serviços, o conhecimento acerca deste processo é importantíssimo para que sejam evitados prejuízos financeiros.

A coleta, análise e organização dos dados realizada na Empresa $X$ possibilitaram o alcance do objetivo e resposta ao questionamento realizado sobre a influência destes custos no resultado, permitindo ainda a identificação das causas principais: o desconhecimento do fluxo interno das importações, falhas nos mapeamentos de custos envolvidos e ainda a falta de expertise da assessoria atualmente contratada para atuar neste processo.

Como proposta de solução para os problemas identificados, sugerimos a implementação da ferramenta $5 \mathrm{~W} 2 \mathrm{H}$ juntamente com a aplicação de treinamento sobre a legislação e fluxo das importações dentro da zona franca de Manaus, sugerimos ainda a contratação de uma assessoria com maior expertise e, se possível, de um colaborador na unidade de Manaus para melhor acompanhamento dos processos, agilizando assim o processo de tomada de decisão e mitigando prejuízos financeiros.

Em face a limitação de tempo para realização deste estudo de caso e do cronograma para aplicabilidade das sugestões propostas, sugere-se para estudos futuros, a avaliação da eficácia da implementação ferramenta $5 \mathrm{~W} 2 \mathrm{H}$ e a obtenção dos resultados das outras ações dispostas no estudo de caso.

RC: 98916

Disponível em: https://www.nucleodoconhecimento.com.br/contabilidade/custos-deimportacao 
Concluímos que o tema apresentado propiciou importante conhecimento para os acadêmicos, onde possibilitou ainda experiência prática, fundamentada nas teorias e ensinamentos repassados pelos mestres do curso de ciências contábeis. Para instituição estudada, viabilizou informações claras e precisas sobre influências diretas em seu resultado do exercício, possibilitando melhorias financeiras e possibilidade de atuação nos pontos fortes e fracos, gerando melhoria dos seus processos.

\section{REFERÊNCIAS}

AUSTIN, Robert D. Measuring and managing performance in organizations. Addison- Wesley, 2013.

BOTELHO, A. J. Redesenhando o projeto: Zona Franca de Manaus. 2. ed. São Paulo: Atlas, 2010.

BRASIL. Constituição da República Federativa do Brasil 1988. Brasília, DF. 1988.

Disponível em:

<http://www.planalto.gov.br/ccivil_03/constituicao/constituicaocompilado.htm>. Acesso em: 25 ago. 2021.

Lei ํo 5.172, de 25 de outubro de 1966. Dispõe sobre o Sistema Tributário Nacional e institui normas gerais de direito tributário aplicáveis à União, Estados e Municípios. Disponível em: < http://www.planalto.gov.br/ccivil_03/leis/15172compilado.htm>. Acesso em: 25 ago. 2021.

. Lei no 5.374 , de 7 de dezembro de 1967. Dispõe sobre o Plano de Valorização Econômica da Amazônia, extingue a Superintendência do Plano de Valorização Econômica da Amazônia (SPVEA), cria a Superintendência do Desenvolvimento da Amazônia (SUDAM). Disponível em: < http://www.planalto.gov.br/ccivil_03/leis/1950-1969/15374.htm>. Acesso em: 19 set. 2021.

RC: 98916

Disponível em: https://www.nucleodoconhecimento.com.br/contabilidade/custos-deimportacao 
. Lei n. 10.406, 10 de janeiro de 2002. Institui o Código Civil. Diário Oficial da União, Brasília, DF, 11 jan. 2002. Disponível em: < http://www.planalto.gov.br/ccivil_03/leis/2002//10406compilada.htm>. Acesso em: 25 ago. 2021.

. Lei no 10.893, de 13 de julho de 2004. Dispõe sobre o Adicional ao Frete para a Renovação da Marinha Mercante - AFRMM e o Fundo da Marinha Mercante - FMM. Disponível em: <http://www.planalto.gov.br/ccivil_03/_ato20042006/2004/lei//10.893.htm>. Acesso em: 24 ago. 2021.

. Lei oㅡ 61.244, de 28 de agosto de 1967. Regulamenta o Decreto-Lei no 288, de 28 de fevereiro de 1967 que altera as disposições da Lei no 3.173, de 6 de junho de 1957 e cria a Superintendência da Zona Franca de Manaus SUFRAMA. Disponível

em: <http://www.planalto.gov.br/ccivil_03/decreto/Antigos/D61244.htm>. Acesso em: 19 set. 2021.

. Decreto-lei ํㅡ 2.404, de 23 de dezembro de 1987. Dispõe sobre o Adicional ao Frete para a Renovação da Marinha Mercante (AFRMM) e o Fundo da Marinha Mercante, e dá outras providências. Disponível em: < http://www.planalto.gov.br/ccivil_03/decreto-lei/Del2404.htm>. Acesso em 23 ago. 2021.

Decreto-lei o 6.759, de 5 de fevereiro de 2009. Regulamenta a administração das atividades aduaneiras, e a fiscalização, o controle e a tributação das operações de comércio exterior. Disponível em: <http://www.planalto.gov.br/ccivil_03/_ato2007-2010/2009/decreto/d6759.htm>. Acesso em 23 ago. 2021.

. Lei Complementar № 124, de 3 de janeiro de 2007. Institui, na forma do art. 43 da Constituição Federal, a Superintendência do Desenvolvimento da Amazônia - SUDAM; estabelece sua composição, natureza jurídica, objetivos, área de competência e instrumentos de ação; RC: 98916

Disponível em: https://www.nucleodoconhecimento.com.br/contabilidade/custos-deimportacao 
dispõe sobre o Fundo de Desenvolvimento da Amazônia - FDA; altera a Medida Provisória no 2.157-5, de 24 de agosto de 2001; revoga a Lei Complementar no 67, de 13 de junho de 1991; e dá outras providências. Disponível em: <http://www.planalto.gov.br/ccivil_03/leis/lcp/lcp124.htm>. Acesso em 19 set. 2021.

. Ministério da Economia. Suframa: Zona Franca de Manaus - ZFM.

Disponível em: <https://www.gov.br/suframa/pt-br/zfm/o-que-e-o-projeto-zfm>. Acesso em: 24 ago. 2021.

Ministério do Desenvolvimento. Portaria № 23, de 14 de julho de 2011. Disponível em: < https://www.gov.br/produtividade-e-comercio-exterior/pt-br/acessoa-informacao/legislacao/portarias-secex/anos-

anteriores/portarias_secex_2011/portaria-secex-23-11-consolidada.pdf>. Acesso em: 24 ago. 2021.

BRANDÃO, Pelágio Pereira. A competitividade do complexo industrial e portuário de Pecém como suporte ao desempenho do comércio exterior do estado do Ceará. 2009. Dissertação (Mestrado em Administração). Faculdade de Administração, Universidade de Fortaleza, Fortaleza, 2009. Disponível em: < https://uol.unifor.br/oul/ObraBdtdSiteTrazer.do?method=trazer\&ns=true\&obraCodigo $=79649>$. Acesso em: 24 ago. 2021.

Bonfim, Ronaldo e Botelho Lissandro (2009), Zona Franca de Manaus Condicionantes do futuro. Manaus: Ed Valer.

Comissão de Pronunciamentos Contábeis - CPC (2010). Disponível em: < http://www.cpc.org.br/CPC/DocumentosEmitidos/Pronunciamentos/Pronunciamento? $\mathrm{ld}=47>$. Acesso em: 26 ago. 2021.

Comissão de Valores Mobiliários (CVM). Disponível em: <http:// www.cvm.gov.br> Acesso em: 26 ago. 2021. 
CREPALDI, Sílvio Aparecido. Contabilidade gerencial: teoria e prática. 5. ed. São Paulo: Atlas, 2011.

EIDELCHTEIN, Cláudio et al. - Manual Prático de Comércio Exterior - 3. ed. - São Paulo: Atlas, 2010.

GUIMARÃES, Ronaldo Maciel; PIMENTA, Cleuza Lúcia. O mundo mudou: a importância do treinamento no momento de crise. CASOTECA Edição Especial: Os impactos da Pandemia no Segmentos do Comércio de Bens, Serviços e Turismo (ISSN: 2675-4703), v. 2, n. 2, 2020.

INTERSABERES. Gestão em logística: Série Técnicos em Logística. $1^{a}$ Edição. Curitiba: Intersaberes, 2014.

JAPIASSÚ, André Miguel. How to prepare and submit abstracts for scientific meetings. Revista Brasileira de Terapia Intensiva, 25 (2): 77-80, 2013.

KEEDI, Samir. ABC do Comércio Exterior: abrindo as primeiras páginas. 4. ed. São Paulo: Aduaneiras, 2012.

LAGIOIA, Umbelina Cravo Teixeira. Fundamentos do Mercado de Capitais. 3. ed. São Paulo: Atlas, 2011.

LEONE, G. S G; LEONE, R. J. G. Curso de Contabilidade de Custo. 4. ed. São Paulo: Atlas, 2010.

LIBÓRIO, D.; TERRA, L. Metodologia Cientifica. São Paulo: Rede Internacional de Universidades Laurete, 2015;

IUdíCIBUS, S., MARTINS, E., GELBCKE, E. R., SANTOS, A. Manual de Contabilidade Societária: Aplicável a todas as sociedades de acordo com as normas internacionais e do CPC. 2a ed. São Paulo: Atlas, 2013.

RC: 98916

Disponível em: https://www.nucleodoconhecimento.com.br/contabilidade/custos-deimportacao 
LUNARDI, A. L. Condições Internacionais de Compra e Venda: Incoterms 2010. 3a ed. São Paulo: Aduaneiras, 2011.

MAIA, Jayme de Mariz. Economia internacional e comércio exterior. 15. ed. São Paulo: Atlas, 2013.

MARION, José Carlos. Analise das demonstrações contábeis: Contabilidade Empresarial / José Carlos Marion. - 6. ed. - São Paulo: Atlas, 2010.

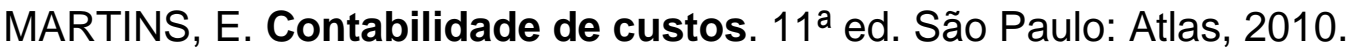

OLIVEIRA, Maria Tereza. Distância psíquica e seus efeitos sobre o fluxo de exportações dos estados brasileiros. 2014. 257 f. Tese (Doutorado em Gestão de Empresas) Universidade de Coimbra, Coimbra, 2014. Disponível em: < http://hdl.handle.net/10316/24975> Acesso em: 24 ago 2021.

OSNI MOURA RIBEIRO. Contabilidade de Custos - 10 Ed. Saraiva Educação S.A., São Paulo, 2017.

PEREIRA, A. S. Metodologia da pesquisa científica [recurso eletrônico] 1. ed. Santa Maria, RS: UFSM, NTE, 2018.

PEREZ, Carlota. Technological revolutions and techno-economic paradigms. Cambridge journal of economics, v.34, p. 185-202, 2010.

QUEIROZ, Renata; APRIGIO, Roseli Ferreira da Silva. Coleção de Importação e Exportação. IOB Folhamatic, 2013.

POLACINSKI, Edio, et al. Implantação dos 5 Ss e proposição de um SGQ para uma indústria de erva-mate. Gestão Estratégica: Empreendedorismo e Sustentabilidade - Congresso Internacional de Administração, 2012. Disponível em <http://www.admpg.com.br/2012/down.php?id=3037\%20\&q=1>. Acesso em: 25 ago. 2021.

RC: 98916

Disponível em: https://www.nucleodoconhecimento.com.br/contabilidade/custos-deimportacao 
REIS, J. G. M. et al. Qualidade em Redes de Suprimentos: A Qualidade Aplicada ao Supply Chain Management. São Paulo: Atlas, 2015.

ROBLES, Léo Tadeu; NOBRE, Marisa. Logística Internacional: uma abordagem para integração de negócios. Curitiba: Intersaberes, 2016.

RFB - Receita Federal do Brasil. Instrução Normativa Secretaria da Receita Federal no 680, de 2 de outubro de 2006. Disciplina o despacho aduaneiro de importação. Diário Oficial da República Federativa do Brasil, Brasília, DF, 5 out. 2006.

Disponível em:

http://normas.receita.fazenda.gov.br/sijut2consulta/link.action?idAto=15618>. Acesso em: 26 ago. 2021.

RFB - Receita Federal do Brasil Manuais Aduaneiros. Disponível em: <https://www.gov.br/receitafederal/pt-br/assuntos/aduana-e-comercioexterior/manuais> Acesso em: 19 set. 2021.

SANTOS, F. A.; VEIGA, W. E. Contabilidade com ênfase em micro, pequenas e médias empresas. São Paulo: Atlas, 2011.

SEGALIS, Gabriel. Tributação no comércio exterior brasileiro: Série comércio exterior e Negócios internacionais. Rio de Janeiro: FGV, 2015.

SILVA, L. F. M. O impacto do warehouse management system (wms) nos indicadores de desempenho logístico: aplicação em centro de distribuição de medicamentos. Dissertação de mestrado. Departamento de Engenharia Industrial, PUC-Rio, Rio de Janeiro, 2012.

SOUSA, José Meireles de. Fundamentos do comércio internacional. São Paulo: Saraiva, 2009.

SUFRAMA. Modelo Zona Franca de Manaus. O que é o Projeto ZFM? 2019. Disponível em: http://www.suframa.gov.br. Acesso em: 17 set. 2021.

RC: 98916

Disponível em: https://www.nucleodoconhecimento.com.br/contabilidade/custos-deimportacao 
STEFANO. Análise dos Custos de Importação. BRTRADING, 2020. Disponível em: $<$ https://brtradingconsult.com.br/analise-dos-custos-de-importacao/>. Acesso em: 24 ago 2021.

TAVARES, Alexandre Macedo. Fundamentos do direito tributário. 4ª ed. São Paulo: Saraiva, 2009.

THESAURUS, Metodologia da Pesquisa Científica: teoria e prática - como elaborar TCC". Brasília: 2016.

TRIGUEIRO, R. de M. Metodologia científica. Londrina: Editora e Distribuidora Educacional S.A., 2014.

VERGARA, S. C.; Projetos e relatórios de pesquisa em administração - 16. Ed. - São Paulo: Atlas, 2016.

VICECONTI, Paulo; NEVES, Silvério das. Contabilidade de Custos um enfoque direto e objetivo. 11.ed. São Paulo: Saraiva, 2013.

VIEIRA, A. Importação: Práticas, rotinas e procedimentos. 4a ed. São Paulo: Aduaneiras, 2010.

Enviado: Setembro, 2021.

Aprovado: Outubro, 2021. 